\title{
Utilization of Long Acting And Permanent Contraceptive Method and Associated Factor Among Women of Reproductive Age in West Guji Zone, Southern Ethiopia, 2018.
}

Eden Dagnachew Zeleke ( $\nabla$ edendagnuz@gmail.com )

Bule Hora University https://orcid.org/0000-0002-2808-2162

Dawit Getachew Assefa

Dilla College: Dilla University

Tigist Tekle Woldesenbet

Hawassa University College of Medicine and Health Sciences

Rediet Gido

Dilla College of Teachers Education: Dilla University

\section{Research}

Keywords: Utilization, Family planning, Contraception, Long Acting And permanent Contraceptive methods

Posted Date: October 12th, 2021

DOI: https://doi.org/10.21203/rs.3.rs-783437/v2

License: (1) This work is licensed under a Creative Commons Attribution 4.0 International License.

Read Full License 


\section{Abstract}

Background: Increasing access to family planning helps to ensure the reproductive right, decrease unintended pregnancy, improve the health and nutritional status of children, reduction of maternal mortality, and enhance longer birth spacing . There is continually low utilization of long-acting and permanent contraceptive methods among low and middle-income countries. The aim of this study was to assess the Utilization of Long-Acting and permanent Contraceptive methods and associated factors among Women of Reproductive Age in the West Guji Zone.

Methods: Hospital-based cross-sectional design was conducted among women of reproductive age in the West Guji Zone. A systematic random sampling method was used to select study subjects for the survey with a sample size of 507. Descriptive analysis was utilized to summarize the data while logistic regression to assess factors influencing the utilization of Long-Acting and permanent Contraceptive methods use. Statistical significance was declared for variables outcomes of the P-value less than 0.05 .

Result: Current utilization of Long-Acting And permanent Contraceptive methods at West Guji zone among the reproductive-aged group was $51.1 \%$. More than the median of participants had negative altitude $(72.4 \%)$ and poor knowledge (57\%) towards the long-acting and permanent contraceptive methods. Educational status of women, the number of alive children, acceptance of utilization of LongActing and permanent Contraceptive methods, how treated by other staff, and waiting time during service delivery are significant determinant factors of long-acting and permanent family planning methods.

Conclusion: Educational status, number of alive children ( Parity) , acceptance of Long-Acting And permanent Contraceptive methods, how treated by other staff, and waiting time to get the service are statistically significant predictors of utilization of long-acting and permanent family planning methods. More than half of women had a negative attitude and poor knowledge of Long-Acting and permanent Contraceptive methods.

\section{Plain English Summary}

Low utilization of long acting and permanent method has been continually reported in low and middle income countries. Unintended pregnancy and unsafe abortion might be related with unmet need of contraceptive.

The aim of this research was to assess level of utilization of long acting and permanent contraceptive method among reproductive aged women in West Guji Zone Ethiopia. The findings from this research will help different stake holder by providing the level of current utilization of long acting and permanent contraceptive methods and help them on planning how to strength the utilization by refereeing the associated factors.

507 Respondents were selected systematically: of which $51.1 \%$ of them utilize one of long acting and permanent contraceptive method currently. 
In conclusion the utilization may be affected by Educational status of women, number of alive children, acceptance of Long-Acting and permanent Contraceptive methods by women, how treated by other staff during service delivery, and waiting time to get the service.

\section{Background}

Family planning allow people to exercise their basic human right to freely decide when to have children, improve families nutrition outcome by limiting their number of children, promote their health and wellbeing, inhibit the distribution of sexually transmitted disease like HIV/AIDS, support women's and girl's education and empowerment and contribute to economic development of the country(1) .

Reproductive age women have been facing enormous challenges related to unmet need of contraceptive which might be because of lack of awareness to protect their health, unavailability of service, lack their decision making role on post ponding child bearing. These obstacles might abort their future promising opportunities and it vast from complications during pregnancy and birth because of unintended pregnancy to lower their education accomplishment which affects their future plan and lead to facing risk for their child (2). Africa (45\%) records the highest proportion of unintended pregnancy next to Latin America (74\%)(2). Although about half of unintended pregnancies in Latin America and in Africa (46\%) results in subsequent unsafe abortion(3). In Ethiopia the unmet need of contraceptive is $15.1 \%$ and only $62.5 \%$ (median) demand for family planning was satisfied with modern methods(4). Large proportion of unintended pregnancy also revealed in Ethiopia urban and rural area i.e. 34\% in Debre Markos (5), Arsi Negele Woreda 41.5\% (6) and 23.5\% in Debre Birhan(7), 36.4\% Addis Ababa (8)and also $29 \%$ in subSaharan Africa (9). According to different studies unintended pregnancy might related with not using contraceptive (10), their knowledge regarding intrauterine device (8) and women autonomy on deciding to use contraceptive $(5,6)$. Unintended pregnancy could be caused by failure to use modern contraceptive methods.

According to WHO 2019 report, global 270 million adolescent have unmet need for contraceptive (11).Greater unmet need of contraceptive showed in sub-Saharan countries compared to the globe. A recent study showed that there is continually low utilization of long acting and permanent contraceptive method among low and middle income countries (10).

Increasing access to family planning helps to ensure the reproductive right, decrease unintended pregnancy, improve health and nutritional status of children, reduction of maternal mortality and enhance longer birth spacing(4) and also decrease the need for unsafe abortion (12).Long acting and permanent contraceptive method have promising effect on ensuring long time protection without need of any further responsibility by the user once applied.

Thus there is a need to assess Utilization of Long Acting And permanent Contraceptive Method and associated factor among Women of Reproductive Age in West Guji Zone. 
The findings obtained from this research can be useful in many ways. Governmental and nongovernmental organizations will take intervention measures and set appropriate plans to improve the existing utilization of long acting and permanent contraceptives by using the identified factors which influences the utilization of LAPMs. And also health managers at a higher level and Health professionals in particular to understand the extent of the utilization level of LAPMs. The findings will also enhance the capacity of planning and decision making to look for possible solutions to solve the problem in collaboration with concerned stake holders so as to provide future appropriate LAPMs services in the Woreda as well as in the west Guji Zone.

\section{Objectives}

\section{General Objective}

- To assess Utilization of Long Acting and permanent Contraceptive methods and associated factor among Women of Reproductive Age in west Guji Zone, 2018.

\section{Specific objectives}

- To determine levels of utilization of long acting and permanent family planning Methods.

- To identify factors associated with utilization of long acting and permanent family Planning methods

\section{Method}

\section{Study area}

The study was conducted in governmental health institutions which are found in Oromia west Guji zone. In west Guji zone there are three hospitals in which two of them were functional (Bule Hora General Hospital \& Kercha primary hospital)\& one is not (Melka Soda Hospital) at the time of study. There were 44 health centers in the zone, of those 3 were nonfunctional.

\section{Study period}

The study was conducted from april15 - May 15, 2018.

\section{Study design}

Hospital based cross sectional design was employed.

\section{Inclusion and exclusion criteria}

\section{Inclusion criteria}

- All women of reproductive age come to the selected health facilities to get Family planning service. 
- Women whose age from 15-49.

\section{Exclusion criteria}

- Women who were not willing to answer.

- Women who were not come to get family planning service

\section{Variables}

\section{Dependent variable}

- Utilization of long acting and permanent family planning methods

\section{Independent variable}

- Age

- Education

- Access to service

- Parity

- Husband opinion

- Satisfaction with information given

- Method accepted

- Knowledge and

- Attitude towards LAPMS of method

\section{Population}

\section{Source population}

All women come to health institution.

Study population

All women come to get family planning service in selected health institution.

\section{Sample size determination and sampling procedure Sample size quantitative data}

A single population proportion formula was used to determine the prevalence of LAPMs by taking proportion of long acting and permanent contraceptive methods in Mekele town, Tigray region, Ethiopia $(p=12.3 \%)(13)$. Other inputs considered was $95 \%$ confidence level, margin of error of $3 \%$ and $10 \%$ nonresponse rate; giving a final sample size of 507.

\section{Sampling technique/procedures}


West Guji zone health facilities were divided in to two (the hospitals \& the health centers). One hospital \& 21 health centers was selected randomly.

\section{Data collection instruments}

A structured and pre tested interview based questionnaire with open ended and closed ended questions was used to collect the data.

\section{Data Processing and Analysis}

Data was entered cleaned, coded and analyzed using SPSS versions 20. Both descriptive and analytical statistical procedures were utilized. Logistic regression was employed to assessment factors influencing the utilization of LAPMs use. Statistical significance was declared for variables outcomes of the P-value less than 0.05 .

\section{Quality control}

The principal investigator was given introduction for the data collectors and supervised all activities for the collected data completeness and clarity if there was any problem; it was addressed on the next day.

\section{Operational definitions}

Very Good Knowledge - those who scored $80 \%$ and above distinct features of LAPMs from knowledge questions.

Good knowledge - those who scored 60 up to $79 \%$ distinct features of LAPMs from knowledge questions.

Poor knowledge - those who scored less than $60 \%$ features of any of the LAPMs from knowledge questions

Positive Attitude - those who scores above mean to the correct answers from attitude measuring LAPMs questions.

Negative Attitude - those who score mean and below mean to the correct answers from attitude measuring LAPMs questions.

\section{Results}

A total of 507 reproductive age women were interviewed from 21 health centers and 1 hospital that found in west Guji zone with $100 \%$ response rate. Socio-demographic characteristics of participants summarized on Table 1. 
Table 1

Socio-demographic characteristics of respondent

\begin{tabular}{|c|c|c|}
\hline VARIABLE & FREQUENCY(NUMBER) & PERCENT \\
\hline \multicolumn{3}{|l|}{ AGE OF THE WOMEN } \\
\hline $15-24$ & 182 & $35.9 \%$ \\
\hline $25-34$ & 283 & $55.8 \%$ \\
\hline $35-49$ & 42 & $8.3 \%$ \\
\hline \multicolumn{3}{|l|}{ RELIGION } \\
\hline Orthodox & 142 & $28 \%$ \\
\hline Muslim & 66 & $13 \%$ \\
\hline Protestant & 294 & $58 \%$ \\
\hline Catholic & 5 & $1 \%$ \\
\hline \multicolumn{3}{|c|}{ EDUCATIONAL LEVEL OF WOMEN } \\
\hline Informal & 47 & $9.3 \%$ \\
\hline Grade 1-8 & 131 & $25.8 \%$ \\
\hline Grade $9-12$ & 143 & $28.2 \%$ \\
\hline College and university & 40 & $7.9 \%$ \\
\hline Illiterate & 146 & $28.8 \%$ \\
\hline \multicolumn{3}{|l|}{ MARTIAL STATUS } \\
\hline Married & 462 & $91.1 \%$ \\
\hline Single & 24 & $4.7 \%$ \\
\hline Divorced & 7 & $1.4 \%$ \\
\hline Widowed & 8 & $1.6 \%$ \\
\hline Separated & 6 & $1.2 \%$ \\
\hline \multicolumn{3}{|l|}{ OCCUPATION } \\
\hline Government employee & 189 & $37.3 \%$ \\
\hline NGO employee & 2 & $0.4 \%$ \\
\hline Private business(merchant) & 72 & $14.2 \%$ \\
\hline House wife & 162 & $32.0 \%$ \\
\hline Student & 40 & $7.9 \%$ \\
\hline
\end{tabular}




\begin{tabular}{|lll|}
\hline VARIABLE & FREQUENCY(NUMBER) & PERCENT \\
\hline Daily laborer & 32 & $6.3 \%$ \\
\hline Farmer & 10 & $2 \%$ \\
\hline MONTHLY INCOME & & \\
\hline$<499$ & 84 & $16.6 \%$ \\
\hline $500-1499$ & 192 & $37.9 \%$ \\
\hline $1500-2499$ & 111 & $21.9 \%$ \\
\hline $2500-3499$ & 84 & $16.6 \%$ \\
\hline $3500-4499$ & 14 & $2.8 \%$ \\
\hline$>4500$ & 22 & $4.3 \%$ \\
\hline
\end{tabular}

Obstetric characteristics of the respondents in west Guji zone Majority of the respondents $404(79.7 \%)$ were found to have married between the age of $14-24$ followed by seventy nine (15.6\%) from $25-35$ with mean \pm (SD), age of participants was $21 \pm$ (3.69) years old. At their first birth $374(73.8 \%)$ of the respondents were 14-24 years old with mean \pm SD of age $22 \pm(3.65)$ years old and $52(10.3 \%)$ of the participants have never given birth yet. Table 2 summarized obstetric history of the participants.

Table 2

Obstetric characteristics of the respondents in west Guji zone

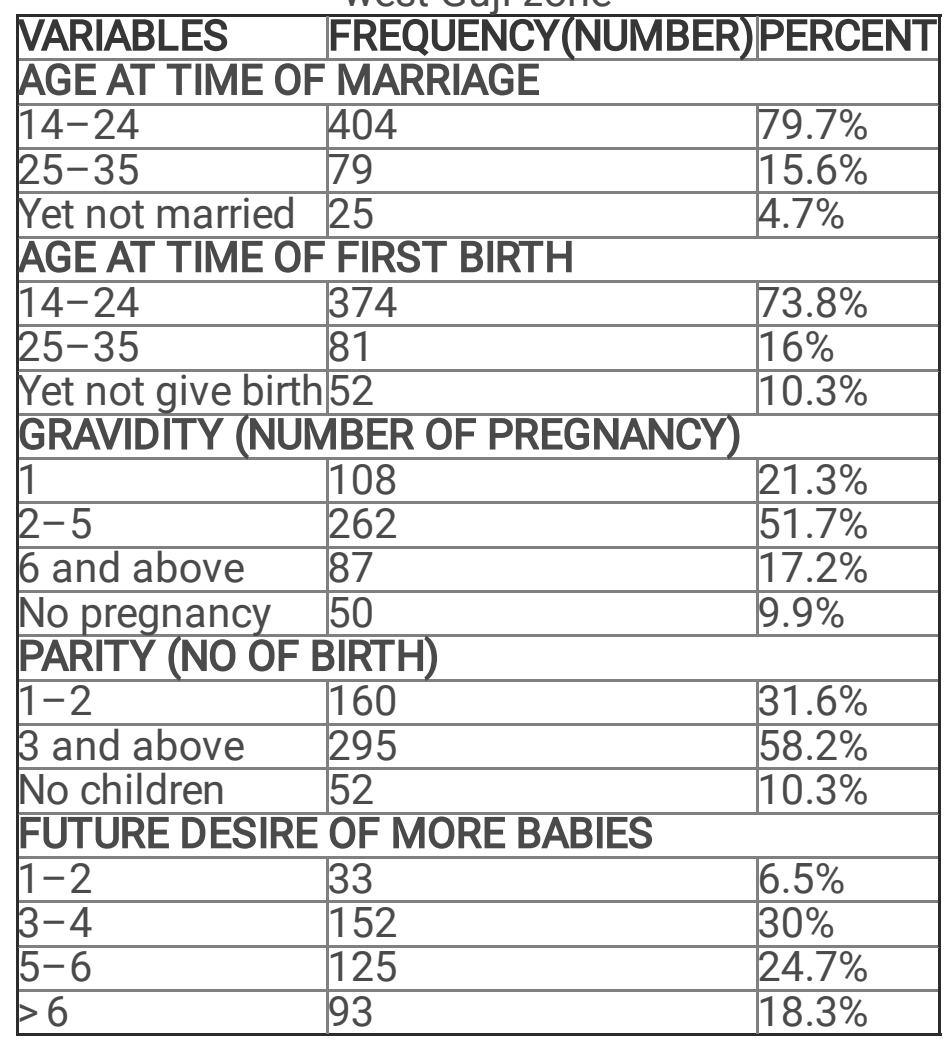


Knowledge of the respondent on long acting and permanent method

Three hundred thirty seven (66.5\%) of women know at least one method of modern family planning method. Injectable followed by implant is the most known method and male sterilization(vasectomy) is the least known among the modern family planning which was 323(63.7\%), 265(52.3\%),and 48(9.5\%) respectively. Two hundred eighty (55.2\%) of women know at least one long acting and permanent family planning method among which implants $277(54.6 \%)$ are the most known and vasectomy $45(8.9 \%)$ is the least known. Table 3 summarized participant's knowledge on the type of modern contraceptive and Long acting and permanent contraceptive method.

Table 3

Knowledge of the respondent on long acting and permanent method in west Guji zone

\begin{tabular}{|l|l|l|}
\hline $\begin{array}{l}\text { Do you know any modern family planning } \\
\text { Methods? }\end{array}$ & Frequency Percent \\
\hline Yes & 337 & $66.5 \%$ \\
\hline Pill as modern family planning & 197 & $38.9 \%$ \\
\hline IUCD as modern family planning & 132 & $26 \%$ \\
\hline Injectable as modern family planning & 323 & $63.7 \%$ \\
\hline Tubal ligation as modern family planning & 58 & $11.4 \%$ \\
\hline Vasectomy as modern family planning & 48 & $9.5 \%$ \\
\hline Implant as modern family planning & 265 & $52.3 \%$ \\
\hline Lactation as modern family planning & 52 & $10.3 \%$ \\
\hline Condom as modern family planning & 133 & $26.2 \%$ \\
\hline $\begin{array}{l}\text { Do you know about LAPMS contraceptive } \\
\text { methods }\end{array}$ & 280 & $55.2 \%$ \\
\hline IUCD as long acting \& permanent method & 126 & $24.9 \%$ \\
\hline Implant as long acting and permanent method & 277 & $54.6 \%$ \\
\hline Tubal ligation as long acting and permanent method 59 & $11.6 \%$ \\
\hline Vasectomy as long acting and permanent method & 45 & $8.9 \%$ \\
\hline
\end{tabular}

Most of the respondents (43\%) were believe that long acting and permanent contraceptive method have used for child spacing and only seventy eight (15.4\%) of the respondent believe that it prevent possible maternal and child death and ill health. The other use of long acting and permanent method preventing unwanted pregnancy and limiting family size are only accepted by $33.1 \%$ and $33.1 \%$ respectively Concerning the level of knowledge one hundred forty seven (29\%) have good knowledge on long acting and permanent contraceptive while seventy one (14\%) and two hundred eighty nine $(57 \%)$ have very good knowledge and poor knowledge respectively. Table 4 summarized knowledge of respondents on LAPMs. 
Table 4

Knowledge of the respondent on LAPMs in west Guji zone

\begin{tabular}{|c|c|c|c|}
\hline & Yes & No & Don’t know \\
\hline Does IUCD can prevent pregnancies for more than 10 year & $215(42.4 \%)$ & $150(29.6 \%)$ & $42(28 \%)$ \\
\hline Do you think IUCD appropriate for female at high risk of ge & & & \\
\hline $\begin{array}{l}\text { IUCD don't interference with sexual } \\
\text { Intercourse or desire? }\end{array}$ & $190(37.5 \%)$ & & 151 \\
\hline $\begin{array}{l}\text { Do you think IUCD is immediately } \\
\text { reversible?(become pregnant quickly when removed) }\end{array}$ & 196(38.7\%) & $156(30.8 \%)$ & $155(30.6 \%)$ \\
\hline IUCD Does not can cause cancer? & $212(41.8 \%)$ & $142(28 \%)$ & $153(30.2 \%)$ \\
\hline $\begin{array}{l}\text { Do you think Implant can prevent } \\
\text { Pregnancies for } 3-5 \text { years? }\end{array}$ & $276(54.4 \%)$ & $80(15.8 \%)$ & $151(29.8 \%)$ \\
\hline $\begin{array}{l}\text { Do Implants require minor surgical } \\
\text { Procedure during insertion and removal? }\end{array}$ & $265(52.3 \%)$ & $90(17.8 \%)$ & $0 \%)$ \\
\hline $\begin{array}{l}\text { Do you think Implants is immediately } \\
\text { Reversible? }\end{array}$ & $242(47.7 \%)$ & $101(19.9 \%)$ & 164 \\
\hline Does Female sterilizati & $215(42$. & & \\
\hline LAPMs do not cause ectopic pregr & $201(39.6 \%)$ & & \\
\hline
\end{tabular}

Altitude of the respondent toward LAPMS

Three hundred eighty one $(75.1 \%)$ of the respondent accept long acting and permanent family planning methods. 276(54.4\%) were supported by their husband. Concerning the level of attitudes, Three hundred thirty seven $(72.4 \%)$ of the respondent have poor altitude toward long acting and permanent family planning methods and one hundred forty $(27.6 \%)$ of the respondent have good altitude. Altitude of respondents on the utilization of LAPMs summarized on Table 5.

Table 5

Attitude of respondents on utilization of LAPMs in west Guji zone, 2018G.C

\begin{tabular}{|c|c|c|c|c|c|}
\hline & $\begin{array}{l}\text { Strongly } \\
\text { disagree }\end{array}$ & disagree & Not sure & Agree & $\begin{array}{l}\text { Strongly } \\
\text { agree }\end{array}$ \\
\hline $\begin{array}{l}\text { The insertion and removal of implant is } \\
\text { highly painful }\end{array}$ & $87(17.2 \%)$ & $100(19.7 \%)$ & $131(2$ & 2.3) & $25(4.9 \%)$ \\
\hline Insertion of IUCD causes loss of pregnancy & 16( & 106( & & 84(3 & $34(6.7 \%)$ \\
\hline Using IUCD prevents from doing heavy work & $40(7.9 \%)$ & $.6 \%)$ & 165 & & \\
\hline $\begin{array}{l}\text { Operation for female sterilization is } \\
\text { dangerous }\end{array}$ & $18(3.6 \%)$ & $110(21.7 \%)$ & 203 & 142 & $34(6.7 \%)$ \\
\hline IUCD and implant cause infertility & $42(8.3 \%)$ & $.4 \%)$ & 186 & 5\%) & $31(6.1 \%)$ \\
\hline The IUCD will get stuck in my uterus & $36(7.1 \%)$ & 147 & & 126 & 19 \\
\hline $\begin{array}{l}\text { Nulliparous women shouldn't have used an } \\
\text { IUCD }\end{array}$ & $47(9.3 \%)$ & 91(17.9\%) & $172(33.9 \%)$ & $163(32.1 \%$ & 34( \\
\hline IUCD will not fit in my uterus & $43(8.5 \%)$ & $153(30.2 \%)$ & 191(37.7\%) & $75(14.8 \%)$ & $45(8.9 \%)$ \\
\hline
\end{tabular}

Practice of long acting and permanent methods

Utilization of long acting and permanent contraceptive method summarized on Table 6. 
Table 6

Practice of respondents on long acting and permanent contraceptive methods of west Guji Zone

\begin{tabular}{|c|c|c|c|}
\hline & & Frequency & percent \\
\hline Have you ever use LAPMs & \begin{tabular}{|l|} 
yes \\
No
\end{tabular} & $\begin{array}{l}217 \\
290\end{array}$ & \begin{tabular}{|l|}
$42.8 \%$ \\
$57.2 \%$ \\
\end{tabular} \\
\hline \multicolumn{4}{|l|}{ Reason for stop using LAPMs } \\
\hline Fear of side effect & & 109 & $21.5 \%$ \\
\hline Partner disapprove & & 111 & $21.9 \%$ \\
\hline Medical problem & & 20 & $3.9 \%$ \\
\hline Shift to other method & & 34 & $6.7 \%$ \\
\hline I want a child & & 25 & $4.9 \%$ \\
\hline Religious opposition & & 22 & $4.3 \%$ \\
\hline Don't know & & 43 & $8.5 \%$ \\
\hline Have you ever use implant? & & 205 & $40.4 \%$ \\
\hline Have you ever use IUCD? & & 12 & $2.4 \%$ \\
\hline Have you ever use vasectomy? & & 0 & $0 \%$ \\
\hline Have you ever use tubal ligation? & & 0 & $0 \%$ \\
\hline Are you currently using LAPMs & \begin{tabular}{|l} 
Yes \\
No
\end{tabular} & $\begin{array}{l}259 \\
248\end{array}$ & \begin{tabular}{|l|l|}
$51.1 \%$ \\
$48.9 \%$ \\
\end{tabular} \\
\hline Implant & & 229 & $45.2 \%$ \\
\hline IUCD & & 25 & $4.9 \%$ \\
\hline Tubal ligation & & 5 & $1 \%$ \\
\hline vasectomy & & 0 & $0 \%$ \\
\hline \multicolumn{4}{|c|}{ Reason for currently using long acting and permanent contraceptive methoc } \\
\hline Have enough child & & 59 & $11.6 \%$ \\
\hline Pressure from my husband & & 37 & $7.3 \%$ \\
\hline Want to space & & 123 & $24.3 \%$ \\
\hline Advice from health professional & & 144 & $28.4 \%$ \\
\hline \multicolumn{4}{|l|}{ Reason for not practicing LAPMS } \\
\hline Fear of side effect & & 113 & $22.3 \%$ \\
\hline Service unavailability & & 9 & $1.8 \%$ \\
\hline Partner disapprove & & 147 & $29 \%$ \\
\hline Medical problem & & 32 & $6.3 \%$ \\
\hline Shift to other method & & 40 & $7.9 \%$ \\
\hline Lack of knowledge & & 79 & $15.6 \%$ \\
\hline
\end{tabular}

One hundred seventy nine (35.3\%) of the respondent were get the service from health center which is followed by sixty four (12.6\%) were get from hospital. The rest were get the service from NGO clinic four $(0.8 \%)$ and health post twelve $(2.4 \%)$.

Perceived service quality of respondents on long acting and permanent contraceptive methods Participant's response on service quality summarized on Table 7. 
Table 7

perceived service quality of respondents on long acting and permanent contraceptive methods of West Guji zone on 2018.

During your visit to health facility how were you treated by the other staff?

How long did you wait to get service at the facility?

How do you feel about your waiting time?

Did the provider ask if you were having a problem with the method that you used?

Have you had a problem with your method?, that you wanted to discuss with your provider

Did the provider try to understand the nature of your problem?

Did the provider suggest what you should do (action you should take) to resolve the problem?

Were you satisfied with the advice or treatment that you received for your problem?

\begin{tabular}{|l|l|l|}
\hline & Frequency & percent \\
\hline Very well & 236 & $46.5 \%$ \\
\hline well & 110 & $21.7 \%$ \\
\hline $\begin{array}{l}\text { Not very } \\
\text { well/poorly }\end{array}$ & 159 & $31.4 \%$ \\
\hline $\begin{array}{l}\text { There was no } \\
\text { other staff }\end{array}$ & 2 & $0.4 \%$ \\
\hline <15minute & 14 & $2.8 \%$ \\
\hline $16-30$ minute & 129 & $25.4 \%$ \\
\hline $31-45$ minute & 122 & $24.1 \%$ \\
\hline $46-60$ minute & 67 & $13.2 \%$ \\
\hline $61-90$ minute & 66 & $13 \%$ \\
\hline $91-120$ minute & 66 & $13 \%$ \\
\hline 120minute & 38 & $7.5 \%$ \\
\hline Don't know & 5 & $1 \%$ \\
\hline No waiting time & 73 & $14.4 \%$ \\
\hline $\begin{array}{l}\text { Reasonable/short } \\
\text { time }\end{array}$ & 218 & $43 \%$ \\
\hline Too long & 209 & $41.2 \%$ \\
\hline Don't know & 7 & $1.4 \%$ \\
\hline Yes & 460 & $90.7 \%$ \\
\hline No & 47 & $9.3 \%$ \\
\hline Yes & 421 & $83 \%$ \\
\hline No & 86 & $17 \%$ \\
\hline Yes & 332 & $65.5 \%$ \\
\hline No & 175 & $48.3 \%$ \\
\hline Yes & 302 & $59.6 \%$ \\
\hline No & 205 & $40.2 \%$ \\
\hline Yes & 443 & $87.4 \%$ \\
\hline No & 64 & $12.6 \%$ \\
\hline
\end{tabular}

\section{Logistic regression analysis of utilization of LAPMs among women of reproductive age group in west}

\section{Guji zone, 2018.}

Variable considered for multiple logistic regression were family size, educational level of women, parity, accept long acting and permanent contraceptive method, ever use LAPM, husband opinion, how treated by other staff, service satisfaction, reasonable waiting time and level of knowledge.

During multiple logistic regression educational level of women, parity, accept LAPM, how treated by other staff during service and waiting time to get the service were significantly associated with current utilization of long acting and permanent contraceptive method. Result of binary and multiple logistic regressions presented on Table 8. 
Table 8

logistic regression analysis of utilization of LAPMs among women of reproductive age group in west Guji zone, 2018.

\begin{tabular}{|c|c|c|c|c|}
\hline \multirow{2}{*}{\begin{tabular}{|l|} 
Variables \\
Family size \\
\end{tabular}} & \multicolumn{4}{|c|}{$\begin{array}{l}\text { utilization of LAPMCOR(95\% CI) } \\
\text { Yes No }\end{array}$} \\
\hline & & & & \\
\hline \multirow{2}{*}{$\begin{array}{l}1-3 \\
\geq 4\end{array}$} & 210 & 225 & & 1 \\
\hline & 49 & 23 & $0.438(0.258-0.744)$ & $1.54(0.21-11.34)$ \\
\hline \multicolumn{5}{|c|}{ Educational level of women } \\
\hline Informal & 21 & 26 & 1 & \\
\hline \begin{tabular}{|l|} 
Grade $1-8$ \\
Grade $9-12$
\end{tabular} & 70 & 61 & $0.704(0.36-1.375)$ & $0.78(0.172-3.53)$ \\
\hline Grade $9-12$ & 115 & 28 & $0.197(0.097-0.399)$ & $0.116(0.023-0.593)^{\star}$ \\
\hline \multirow{2}{*}{ College or university } & 30 & 10 & $0.269(0.12-0.674)$ & $0.446(0.055-3.644)$ \\
\hline & \multicolumn{4}{|c|}{ Parity } \\
\hline \multirow{2}{*}{$\begin{array}{l}1-2 \\
\geq 3\end{array}$} & 45 & 1115 & & 1 \\
\hline & 192 & 103 & $0.210(0.138-0.319)$ & $0.082(0.026-0.253)^{\star}$ \\
\hline \multicolumn{5}{|l|}{ Accept LAPM } \\
\hline \multirow{2}{*}{\begin{tabular}{|l|} 
Yes \\
No
\end{tabular}} & 239 & 142 & & 1 \\
\hline & 20 & 106 & $0.112(0.067-0.189)$ & $0.029(0.005-0.162)^{\star}$ \\
\hline \multicolumn{5}{|l|}{ Husband opinion } \\
\hline Support & 164 & 1112 & 1 & 1 \\
\hline \multirow{2}{*}{\multicolumn{5}{|c|}{\begin{tabular}{|l} 
Oppose \\
How treated by other sta
\end{tabular}}} \\
\hline & & & & \\
\hline $\begin{array}{l}\text { Well } \\
\text { Not verv well }\end{array}$ & 234 & 112 & 1 & 1 \\
\hline Not very well & 25 & 136 & $0.088(0.054-0.143)$ & $0.06(0.017-0.213)^{\star}$ \\
\hline \multicolumn{5}{|c|}{ Reasonable waiting time } \\
\hline \multicolumn{2}{|c|}{ No Waiting time 42} & 31 & $0.143(0.079-0.25$ & $0.098(0.026-0.376)^{\star}$ \\
\hline \multirow{2}{*}{$\begin{array}{l}\text { Reasonable / short } \\
\text { Too long } \\
\text { Service satisfaction }\end{array}$} & 182 & 36 & $0.038(0.023-0.064)$ & $005-0.087)^{\star}$ \\
\hline & 35 & 181 & 1 & 1 \\
\hline \multicolumn{5}{|l|}{ Service satisfaction } \\
\hline \multirow{2}{*}{\begin{tabular}{|l} 
Yes \\
No
\end{tabular}} & 222 & 187 & $0.511(0.325-0.803)$ & $1.1(0.28-4)$ \\
\hline & 37 & 61 & 1 & 1 \\
\hline \multicolumn{5}{|l|}{ Ever use LAPM } \\
\hline \multirow{2}{*}{\begin{tabular}{|l|} 
Yes \\
No
\end{tabular}} & 130 & 87 & $0.536(0.375-0.766)$ & $0.94(0.33-2.68)$ \\
\hline & 129 & 161 & 1 & \\
\hline \multicolumn{5}{|l|}{ Level of knowledge } \\
\hline \multirow{3}{*}{\begin{tabular}{|l} 
Poor knowledge \\
Good knowledge \\
Very good knowledge \\
\end{tabular}} & 1115 & 174 & 1 & 1 \\
\hline & 41 & 30 & $0.484(0.286-0.819)$ & $1.04(0.21-5.2)$ \\
\hline & 103 & 44 & $0.282(0.185-0.432)$ & $0.5(0.166-1.58)$ \\
\hline
\end{tabular}

\section{Discussion}

The finding of these study indicate that educational status women, number of alive children (parity ) ,accept utilization of LAPMs, how treated by other staff during service delivery and waiting time for service are significant determinant factor of long acting and permanent family planning method.

In this study the overall the current use of LAMP at west Guji zone was $51.1 \%$. This is very high when compared to research done in Bombe district, Debre Berhan District, Dendi district and Janamora District which were $16.3 \%, 27.3 \%, 17.6 \%$ and $12.9 \%$ respectively $(14-17)$ and which is less than the study done in Ilu Aba Bor Zone and Ambo town that is $62.2 \%$ and $65.6 \%$ respectively $(18,19)$. This difference could be in study setting, time of the study, the deployments of health extension worker which strengthen the awareness of LAPMs at community level and the government attention towards these methods increases the utilization. 
Another factor affecting utilization of long acting and permanent family planning method is educational level of women. Women who join high school (Grade 9-12) 0.116 time AOR 0.116(0.023-0.593) more likely use long acting and permanent contraceptive method than women with informal education. This is comparable with the study done at Bombe district women who have educational level primary (1-8) / above AOR 3.7 95\% Cl:(1.7-7.9) more likely to use LAPMs than women had no formal education (14).

In this study 337 (65.5\%) of women know at least one method of modern family planning method which is very low when compared to the study done at Debre Berhan Town which is (459) $92 \%$ of the respondents were able to mention at least one method of modern family planning method (20). The least known method as LAPMs is vasectomy (8.9\%) and implant were very known method under LAPMs (54.6\%) which is followed by IUCD $24.9 \%$ and tubal ligation (11.6\%). These is very low when compared to the study done at Gesuba town in which vasectomy is least known (16.6\%) and Implant is most known which is followed by IUCD and tubal ligation which is $69.3 \%, 47.9 \%$ and $18.8 \%$ respectively(21).

In this study women who didn't accept utilization of long acting and permanent methods $97.1 \%$ less likely to use LAPMS AOR $=0.02995 \% \mathrm{Cl}(0.005-0.162)$ than women who accept.

women with more than three live children $91.8 \%$ less likely to use LAPMs than those who had 1-2 live children with AOR $=0.08295 \% \mathrm{Cl}(0.026-0.253)$ which is contradicted when compared to the study done at Debre Berhan District, women with 3 and above and 1 child is 2 times more likely to use LAPMs than who had no children with $A O R=2.41(0.14-41.43$ and $A O R=2.7495 \% \mathrm{Cl}:(0.22-34.62)$ respectively (15).

Regarding quality of service, women who were treated not very well with other staff $94 \%$ less likely use long acting permanent contraceptive method than those treated very well with $\mathrm{AOR}=0.0695 \% \mathrm{Cl}(0.017-$ 0.213). Women who believes there were no waiting time and reasonable waiting time for getting the service 0.098 and 0.022 time use long acting and permanent contraceptive method than women who believed waiting time was too long with AOR $=0.09895 \% \mathrm{Cl}(0.026-0.376)$ and $\mathrm{AOR}=0.02295 \% \mathrm{Cl}$ (0.005-0.087).

Regarding the altitude of participants towards long acting and permanent contraceptive method, our finding was higher than finding from Debre Berhan District in which $52.5 \%$ had negative altitude.

\section{Conclusion}

In conclusion above median of participants has used long acting and permanent contraceptive method. Educational status, number of alive children (Parity), acceptance of LAPMs, how treated by other staff and waiting time to get the service are statistically significant predictors of utilization of long acting and permanent family planning methods. More than half of women had negative altitude and poor knowledge on LAPMS.

\section{Recommendation}


- Responsible bodies shall work together to improve women knowledge and altitude towards long acting and permanent family planning method.

- Hospitals shall improve their service delivery in order to increase the utilization of long acting and permanent family planning methods.

\section{Abbreviations}

AOR-Adjusted Odds Ratio; COR-Crudes Odds Ratio; FGD-Focused Group Discussion; IUCD-Intrauterine Contraceptive Device; LAPM-Long Acting and Permanent Method; SD-Standard Deviation; WHO-World Health Organization.

\section{Declarations}

\section{Acknowledgement}

We would like thank Bule Hora University for supporting this study.

\section{Ethics approval and consent to participate}

Ethical clearance was obtained from Bule Hora University, Research and publication directorate. Verbal consent was obtained from individual participants. All the participant in the questionnaire survey was told about their participation could be on a voluntary basis and their information will be kept confidential and the name of the participants was not taken.

\section{Consent for publication}

Not applicable.

\section{Availability of data and materials}

Data will be available upon request from the correspondence authors.

\section{Competing interests}

The authors declare that they have no competing interests.

\section{Funding}


This research was financially supported by Bule Hora University.

\section{Authors' contributions}

EDZ conceptualized the study. EDZ, DGA, RG and TTW developed the protocol, collect and coordinated data collection, and carried out the statistical analysis and drafted the manuscript. All authors read and approved the final manuscript.

\section{References}

1. Starbird E, Norton M, Marcus R. Investing in Family Planning: Key to Achieving the Sustainable Development Goals. Global health. science practice. 2016;4(2):191-210.

2. et.al JED. ADDING IT UP: Costs and Benefits of Meeting the Contraceptive Needs of Adolescents. 2016.

3. WHO. https://apps.who.int/iris/bitstream/handle/10665/255862/WHO-RHR-17.10eng.pdf;sequence $=1$.

4. Family Planning. and the 2030 Agenda for Sustainable Development • Data Booklet.

5. Nigussie K, Degu G, Chanie H, Edemealem H. Magnitude of Unintended Pregnancy and Associated Factors Among Pregnant Women in Debre Markos Town, East Gojjam Zone, Northwest Ethiopia: A Cross-Sectional Study. International journal of women's health. 2021;13:129-39.

6. Fite RO, Mohammedamin A, Abebe TW. Unintended pregnancy and associated factors among pregnant women in Arsi Negele Woreda, West Arsi Zone, Ethiopia. BMC Res Notes. 2018;11(1):671.

7. Getu Melese K, Gebrie MH, Berta Badi M, Fekadu Mersha W. Unintended Pregnancy in Ethiopia: Community Based Cross-Sectional Study. Obstetrics gynecology international. 2016;2016:4374791.

8. et.alTK. Magnitude and factors associated with unintended pregnancy among pregnant women in Addis Ababa, Ethiopia. GLOBAL JOURNAL OF MEDICINE AND PUBLIC HEALTH; 2017.

9. Ameyaw EK, Budu E, Sambah F, Baatiema L, Appiah F, Seidu AA, et al. Prevalence and determinants of unintended pregnancy in sub-Saharan Africa: A multi-country analysis of demographic and health surveys. PloS one. 2019;14(8):e0220970.

10. Bellizzi S, Mannava P, Nagai M, Sobel HL. Reasons for discontinuation of contraception among women with a current unintended pregnancy in 36 low and middle-income countries. Contraception. 2020;101(1):26-33.

11. Kantorova V, Wheldon MC, Ueffing P, Dasgupta ANZ. Estimating progress towards meeting women's contraceptive needs in 185 countries: A Bayesian hierarchical modelling study. PLoS Med. 2020;17(2):e1003026.

12. WHO. Contraceptive. https://apps.who.int/iris/bitstream/handle/10665/329884/WHO-RHR-19.18eng.pdf?ua $=1$. 
13. al. Ae. Factors associated with utilization of long acting and permanent contraceptive methods among married women of reproductive age in Mekelle town, Tigray region, north Ethiopia. BMC Pregnancy and Childbirth. 2012;12(6).

14. Geta W, Asseffa NA, Mekonnen N. Utilization of Long Acting and Permanent Contraceptive Methods and Associated Factors among Married Childbearing Age Women in Bombe District, Southern Ethiopia. Reproductive System \& Sexual Disorders. 2018;07(01).

15. B WA. T, M K, S G, K K. Acceptance and Positive Attitude Increased Utilization of Long Acting and Permanent Family Planning Methods Among Reproductive Age Group Women from Debre Berhan District, Ethiopia: Quantitative and Qualitative Analysis. Journal of Community Medicine \& Health Education. 2017;07(04).

16. al. Se. Determinants-of-long-acting-reversible-contraceptives-use-among-childbearing-age-women-indendi-district-western-ethiopia. J Women's Health Care 2015;4(4).

17. Getahun DS, Wolde HF, Muchie KF, Yeshita HY. Utilization and determinants of long term and permanent contraceptive methods among married reproductive age women at Janamora district, northwest Ethiopia. BMC Res Notes. 2018;11(1):836.

18. et.alEY. Determinants of Long Acting and Permanent Family Planning Methods Utilization among Women of Reproductive Age in Ilu Aba Bor Zone, South West Ethiopia, 2016. Journal of Medical Research and Health Education. 2018;2.

19. Ketema Kenassa Joti Tf. Assessment of factor influencing utilization of long acting and permanent methods among married women (18-49 years) of reproductive age in Ambo Town. Oromia Region ,Ethiopia; 2014.

20. Alemu Abajobir A. Intention to use Long-acting and Permanent Family Planning Methods among Married 15-49 years Women in Debremarkos Town, Northwest Ethiopia. Family Medicine \& Medical Science Research. 2014;03(04).

21. et.al FB. Knowledge, Attitude and Factors Associated with the Use of Long Acting and Permanent Contraceptive Methods among Women of Reproductive Age in Gesuba Town, Southern Ethiopia. Journal of Biology, Agriculture and Healthcare. 2015;5. 